\title{
Gastric cancer screening programme in Japan: how to improve its implementation in the community
}

\author{
Binyan Wang, Hiroshi Yanagawa, Kiyomi Sakata
}

\begin{abstract}
Study objective - The aim was to investigate which factors in the operating procedure of the gastric cancer screening programme carried out by local Japanese municipalities affect the participation rate.

Design - This was a cross-sectional study. Data were mainly obtained by questionnaire completed by the person in charge of health in each municipal council. Information was sought on screening motivation, screening programme organisation, payment for the examination, the scheduling and filing system, and community manpower. Data on the participation levels were obtained from the health data service system published by the Ministry of Health and Welfare in 1991.
\end{abstract}

Setting - All of Japan's 3268 local municipalities were sent the questionnaire. Altogether 2795 municipalities responded ( $85.5 \%$ response rate).

Subjects - The local municipality was regarded as the study unit. The municipalities were classified into two groups small municipalities, those with $<10000$ population aged 40 years and over, and large municipalities, those with $>10000$ population aged 40 years and over.

Main results - The participation rate in the screening programme varied according to the municipality population size and age. Small municipalities had higher participation rates. The rate in people aged 60-69 years was highest and that in those aged $70+$ years was lowest. The participation rate was positively associated with factors related to the operating procedure before (for example, giving information about screening), during (for example, assisting the screening staff), and after (setting up the relevant filing systems) the gastric examination. Conclusion - The results suggest that personal motivation, manpower in local residents' organisations, scheduling time for convenience, and a basic filing system for individual data, especially for people who have not participated in the programme for a few years, are important in increasing participation.

( $\mathcal{F}$ Epidemiol Community Health 1994;48:182-187)
In 1957 the Ministry of Health and Welfare in Japan introduced a long term cancer prevention strategy to confront the radical change in the causes of death in the population of Japan. Gastric cancer screening was carried out first and is the most common screening programme throughout the country. ${ }^{1}$ Mortality from stomach cancer has been the highest among cancer deaths for more than 40 years, but since 1975 this rate has been falling. ${ }^{23}$ Many studies have pointed out two causes for the decline the improvement in diet and the early detection of stomach cancer by mass screening. ${ }^{4}$

In 1983 the Health and Medical Services for the Aged Act was passed, and has greatly furthered implementation of the cancer prevention strategy. According to the act, screening for stomach, cervical, breast, and lung cancers is to be provided to elderly and middle aged people who want to have the examination. ${ }^{5}$ The level of participation in the gastric cancer screening programme increased from $8 \%$ in 1984 to $13 \%$ in $1990,{ }^{6}$ but could be increased further. To improve the efficiency of the screening programme and strengthen the cancer prevention strategy, the level of participation must be increased. For those concerned with the planning, organisation, and implementation of the health care system, it is necessary to identify those factors in the operating process of the programme that encourage or discourage people from using it. This study aimed to do this.

\section{Methods}

In February 1991 we sent questionnaires to all of Japan's 3268 municipal councils (655 cities, 2003 towns, 587 villages, and 23 special wards in the Tokyo metropolitan area) to obtain information about how they were carrying out the cancer screening programmes which had been provided for in the Health and Medical Service for the Aged Act of 1983. Each item in the questionnaire (table 1) describes different methods used in the implementation of these programmes. Public health nurses were asked to fill in the questionnaire. For municipal councils which did not employ a public health nurse (fewer than $10 \%$ ), ${ }^{6}$ staff in charge of the health department filled in the questionnaire. Of the 3268 questionnaires sent out, 2800 were returned completed. Five municipalities had not conducted a gastric cancer screening programme despite the act, which left 2795 municipalities $(85.5 \%$ of all those in Japan) for the data analysis. 
Table 1 Features of the gastric cancer screening programme detailed in the questionnaire in a nationwide survey of Japan in 1991

(1) Operating style

Mass screening using special screening mobile units

Individual screening at clinics or hospitals, or both

A combination of the above

(2) Should the programme be entrusted to other institutions?

If yes, should these institutions do all of the screening or a part of it?

Which institutions - screening agencies, public health centres, local medical associations, Which institut

(3) Should screening be conducted outside the usual office hours? If yes, when?

(4) Should screening be conducted at the same time as other screening programme(s)? If yes, with which programme(s)?

(5) How should information about the screening programme be given to residents? Newsletters to residents Local organisation activities House to house circulars Letters or postcards to individuals Home visits from public health nurses Telephone calls Television, radio, the media

(6) Should anyone be exempt from paying a part of the cost of screening?

Those who are in high risk groups (for example $\geq 70$ years) should be exempt Those who are in high risk groups

(7) Should there be systems for keeping individual information on screening results? Individual filing system with or without a computer(s)? Records of those who have not participated for $\geq 3$ years?

Information on whether to undergo detailed examinations if necessary?

(8) Should the cooperation of volunteer groups be sought and if "yes" how?

Providing schedule information to residents

Distributing questionnaires before the screening

Encouraging residents to participate

Aiding operation of the screening

Returning results of the screening to participants

Encouraging those who need detailed examinations to undergo them large municipality means a municipality whose total population size $\geq 25000(10000 / 0 \cdot 4)$. The 2795 municipalities consist of 1973 $(70 \cdot 6 \%)$ small municipalities, and $822(29 \cdot 4 \%)$ large municipalities.

FEATURES EXCLUDED FROM ANALYSIS

All the methods of operating the programme detailed in the questionnaire were considered to be factors that could affect the participation rate. According to the primary report on this research, ${ }^{8} 98.8 \%$ of the municipalities provided mass screening programmes. Altogether $92.7 \%$ of municipalities entrusted some institutions with screening because of the limitations of health manpower and medical equipment, and the part fee for the screening, where the person was not exempt from paying, was not considered to be so high that it would affect the decision to participate or not. These three did not seem helpful in explaining any variation in the participation level and were therefore excluded from the association analyses.

INDEPENDENT AND DEPENDENT VARIABLES

The other five features in the questionnaire (nos 3-8 in table 1), totalling 27 items, were included in the analyses as the independent variables. The dependent variables are the six group participation rates - the large municipality group, the small municipality group, and the $40-49,50-59,60-69$, and $70+$ years age groupings in the small municipality group. Analysis of the large municipalities in relation to age might lead to unreliable results because of the low proportion of large municipalities. screening programmes in the four age groups has to be reported to the government by each municipality according to the act and this comprises the data pool in the WISH system. The denominator of the rate is based on the national census report in $1990 .^{7}$ Since the target population in this screening programme was that above 40 years of age, the data on the population aged over 40 years were used for this study.

Since the participation level ranged from $10-15 \%$ and the goal for the next five year plan was set at $30 \%$, we considered a level of $20 \%$ would be a suitable definition of a high rate for any one municipality. Thus, the participation rate is classified by $20 \%$ into a binary dependent variable in the association analyses.

\section{CONFOUNDING}

To control for population confounding of the observed effect of the operating methods on the participation level, populations were placed in one of two groups according to whether they had fewer or more than 10000 people aged $\geq 40$ years of age. The municipalities with a population $<10000$ are considered to be a small municipality and those with $\geq 10000$ are a large municipality. Since $40 \%$ of the total population is aged 40 or above, a

\section{STATISTICAL ANALYSIS}

For each population size group and each age group, two stages of analyses were conducted: (1) using the Mantel-Haenzel's $\chi^{2}$ test for assessing the association between each factor and each dependent variable; and (2) using logistic regression models for assessing the association between each dependent variable and each set of independent variables. The factors comprising the set satisfied the following three conditions after the first stage of analyses. The three conditions were: (1) an odds ratio $>1.20$ or $<0.80$; (2) by $\chi^{2}$ test, $\mathrm{p}<0.05$; and (3) the representative items in five features. Population size was again used in logistic regression analyses for further adjustment. All analyses were performed with SAS statistical software.

\section{Results}

Participation rates in the gastric cancer screening programme in relation to the age and population size of municipalities are shown in figure 1 . The overall average rate is $14.3 \%$. The rate is highest in the 60-69 years age group, and lowest in the $70+$ years group. The rate in small municipalities is approximately 


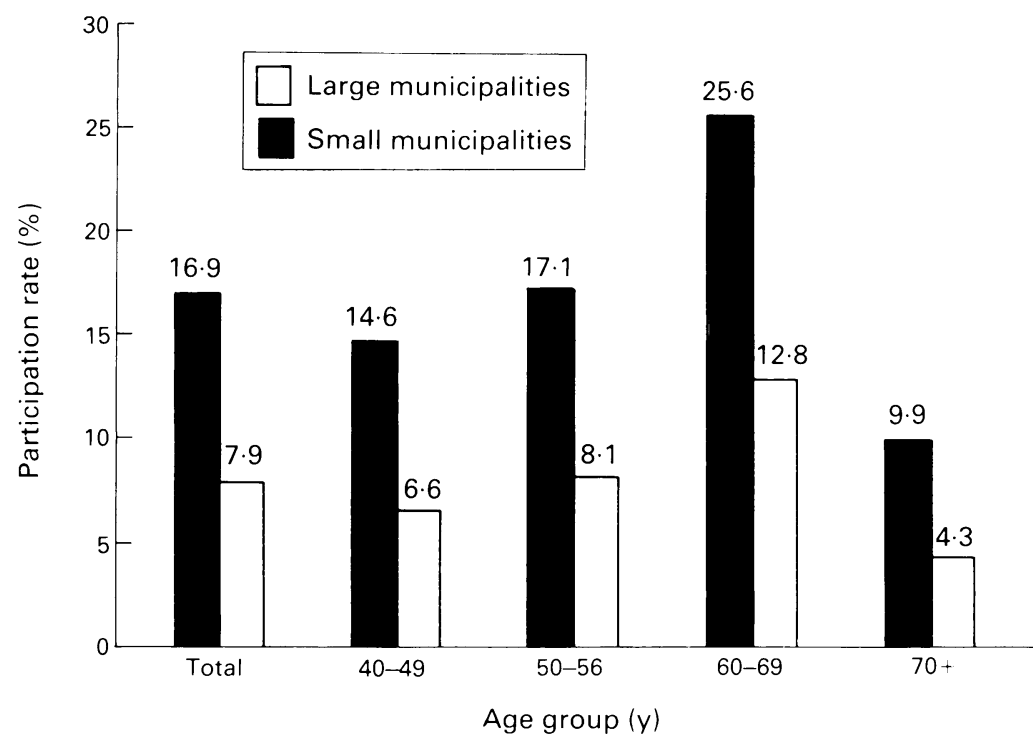

Figure 1 Participation rates for the gastric screening programme in relation to age groups and population size of the municipality $(<10000$ or $>10000)$.

twice as high as those in large municipalities for all age groups.

Figure $2(\mathrm{~A}-\mathrm{C})$ shows the different participation rates for all age groups in this study, in high rate municipalities according to the way in which the residents were notified of the screening programme and the schedule. Notifications were classified into three categories, direct personal contact, indirect personal contact, and impersonal contact. The first comprised local organisation activities, home visits by public health nurses, and telephone calls; the second personal letters or postcards; and the third newsletters, house to house circulars, radio, and TV. The figures show that the more personal and more direct the contact, the higher the participation for the high rate municipalities.

After the first step analyses and the selection according to the three conditions (detailed in the Methods section), 10 factors in the large municipality group and nine factors in the small municipality group were used for each multiple logistic regression analysis. The results are shown in tables 2 and 3 . Three factors show strong positive associations with the participation rates in both population groups.
These are "keeping records of those who had not participated in the screening for $\geq 3$ years", "providing programme information through local organisation activities", and "providing screening outside office hours". In addition, "setting up a filing system of the records for individuals" shows a strong positive association within the small population group. Within the large group, "setting up a filing system of the screening data with the use of a computer" shows a strong positive association. There is also a strong negative factor in each group. In the small municipality group, the factor is "providing the programme information by house to house circulars". In the large municipality group the factor is "providing screening outside office hours on Sundays or national holidays".

In table 4, four factors show a strong positive association with the participation rate in all age groups in small municipalities. These are, "keeping records of those who had not participated in the screening $\geq 3$ years", "providing screening outside usual office hours", and "getting the cooperation of the local organisation". One factor shows a negative association - "providing the programme information by house to house circulars". It should also be noticed that two factors are associated in a strongly positive way in certain age groups. For the 40-49 years group, the factor is "conducting the screening at the same time as the general health examination programme'. For the 60-69 and $70+$ years age groups, the factor is "getting the cooperation of the local organisation". Furthermore, the associations between the participation levels and the factors are generally strongest in the 60-69 years group and weakest in $70+$ years group.

\section{Discussion}

This study shows that the participation rate in the gastric cancer screening varies according to the population size of the municipality and the age. It also shows that the rate is associated with several aspects of the operating procedure of this programme, some of which are relevant to all age groups and others only in certain age groups. The influence of the operating methods can be observed before (in organising

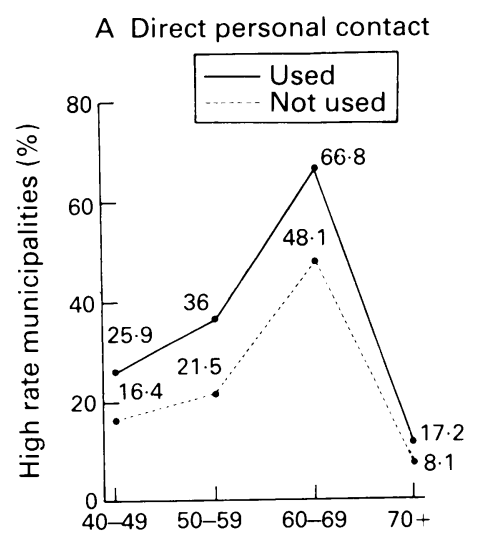

B Indirect personal contact
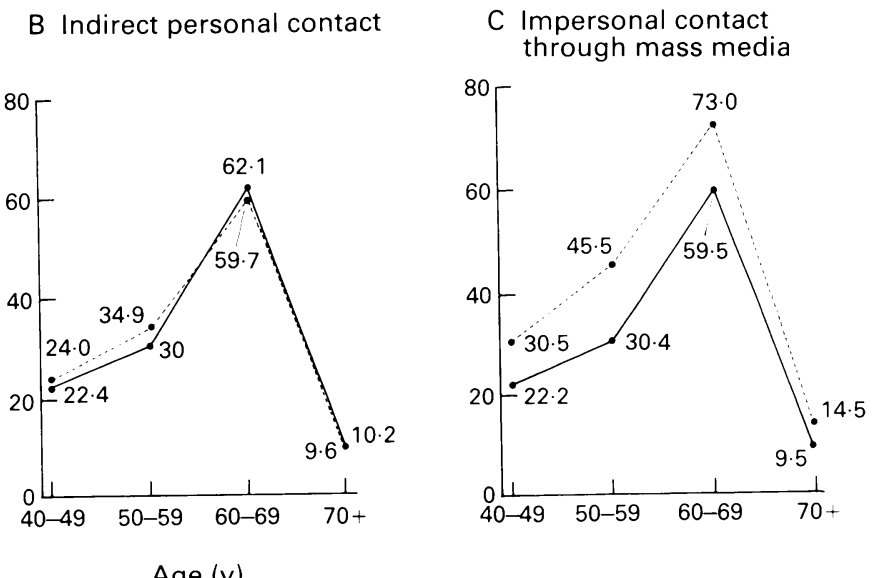

Age $(y)$

Figure 2 Participation rates in high rate municipalities in relation to how residents were told about the programme. 
and informing people about the screening), during (in assisting the screening staff), and after (in setting up the relevant filing systems) the gastric examination in this programme. The results and their practical importance can be understood more clearly if the following is borne in mind.

One issue influencing the participation rate concerned the way information on the programme is provided, and the influence of social

Table 2 The participation rate in the gastric cancer screening programme and factors* relevant to this in the "small" municipality group $(<10000$ population $)$

\begin{tabular}{|c|c|c|}
\hline Factors & Odds ratio $(95 \% C I)$ & p Value \\
\hline $\begin{array}{l}\text { Information about screening schedules given by house to } \\
\text { house circular }\end{array}$ & $0.69(0.62,0.77)$ & $<0.01$ \\
\hline Keeping records of those who have not been screened for & $1.36(1.21,1.53)$ & $<0.01$ \\
\hline Providing screening outside the usual office hours & $1.26(1.10,1.43)$ & $<0.01$ \\
\hline $\begin{array}{l}\text { Providing programme information through local } \\
\text { organisation activities }\end{array}$ & $1.25(1.10,1.42)$ & $<0.01$ \\
\hline Setting up filing system of individual records & $1 \cdot 23(1 \cdot 11,1 \cdot 37)$ & $<0.01$ \\
\hline $\begin{array}{l}\text { Setting up filing system of the screening data with } \\
\text { computer }\end{array}$ & $1 \cdot 14(1.02,1.28)$ & 0.0238 \\
\hline $\begin{array}{l}\text { Providing gastric screening with other screening } \\
\text { programme(s) at the same time }\end{array}$ & $1.13(0.95,1.35)$ & $0 \cdot 1767$ \\
\hline $\begin{array}{l}\text { Getting the cooperation of local organisations } \\
\text { Population size }(n=1832)\end{array}$ & $\begin{array}{l}1.09(0.92,1.28) \\
0.58(0.52,0.66)\end{array}$ & $\begin{aligned} & 0.3092 \\
< & 0.01\end{aligned}$ \\
\hline
\end{tabular}

* The results were analysed by the multiple logistic regression.

Note: $\chi^{2}$ for the likelihood ratio $=292 \cdot 90(p=0 \cdot 1617>0 \cdot 10)$.

Table 3 Participation rate of the gastric cancer screening programme and factors* relevant to it in "large" municipalities ( $\geq 10000$ population)

\begin{tabular}{llc}
\hline Factors & Odds ratio $(95 \%$ CI) & p Value \\
\hline $\begin{array}{l}\text { Providing programme information through local } \\
\text { organisation activities }\end{array}$ & $1.46(1.16,1.84)$ & $<0.01$ \\
$\begin{array}{l}\text { Keeping records of those who have not been screened for } \\
\quad 3 \text { years }\end{array}$ & $1.42(1.01,2.01)$ & $<0.05$ \\
$\begin{array}{l}\text { Setting up filing system of the screening data with } \\
\text { computer }\end{array}$ & $1.36(1.10,1.68)$ & $<0.01$ \\
$\begin{array}{l}\text { Providing screening outside usual office hours (in morning) } \\
\text { Providing screening outside usual office hours (on Sundays }\end{array}$ & $1.29(1.04,1.59)$ & $<0.05$ \\
$\begin{array}{l}\text { or national holidays) } \\
\text { Providing programme information by personal letter }\end{array}$ & $0.75(0.55,1.04)$ & 0.0857 \\
Providing screening outside usual office hours (on & $0.90(0.73,1.13)$ & 0.3977 \\
$\begin{array}{l}\text { Saturdays) } \\
\text { Providing programme information by house to house }\end{array}$ & $0.91(0.75,1.11)$ & 0.3390 \\
$\begin{array}{l}\text { circulars } \\
\text { Setting the cooperation of local organisations }\end{array}$ & $1.13(0.88,1.46)$ & 0.3405 \\
Population size (n=593) & $1.05(0.85,1.28)$ & 0.6356 \\
\hline
\end{tabular}

* The results analysed by the multiple logistic regression

Note: $\chi^{2}$ for the likelihood ratio $=316 \cdot 41(p=0.2864>0 \cdot 10)$

Table 4 The age specific participation rates for the gastric cancer screening programme and their relevant factors* in the small municipality group $(<10000$ population)

\begin{tabular}{|c|c|c|c|c|}
\hline \multirow[t]{2}{*}{ Factors } & \multicolumn{4}{|c|}{ Odds ratio for each age } \\
\hline & $40 s$ & $50 s$ & $60 s$ & $\geq 70 s$ \\
\hline $\begin{array}{l}\text { Keeping records of those who have not been } \\
\text { screened for } \geq 3 \text { years }\end{array}$ & $1 \cdot 35 \dagger$ & $1 \cdot 40 \dagger$ & $1 \cdot 53 \dagger$ & $1 \cdot 25 \dagger$ \\
\hline $\begin{array}{l}\text { Setting up filing system of the records for } \\
\text { individual subjects }\end{array}$ & $1 \cdot 22 \dagger$ & $1 \cdot 25 \dagger$ & $1 \cdot 25 \dagger$ & $1 \cdot 18 \dagger$ \\
\hline $\begin{array}{l}\text { Setting up filing system of the screening data on } \\
\text { computer }\end{array}$ & - & $1 \cdot 12$ & $1 \cdot 21 \dagger$ & $1 \cdot 19 \dagger$ \\
\hline Providing screening outside usual office hours & $1.39 \dagger$ & $1.35 \dagger$ & $1.28{ }^{\dagger}$ & $1.23 \dagger$ \\
\hline $\begin{array}{l}\text { Getting the cooperation of local voluntary } \\
\text { organisations }\end{array}$ & $1.21^{\dagger}$ & $1 \cdot 20 \dagger$ & $1.29 \dagger$ & $1.20 \dagger$ \\
\hline $\begin{array}{l}\text { Providing gastric screening with other screening } \\
\text { at the same time }\end{array}$ & - & - & $1 \cdot 13$ & $1 \cdot 02$ \\
\hline $\begin{array}{l}\text { With GHE } \\
\text { With BSC }\end{array}$ & $1 \cdot 29+$ & - & - & - \\
\hline $\begin{array}{l}\text { Providing programme information by house to } \\
\text { house circulars }\end{array}$ & $\overline{0} \cdot 75+$ & $\begin{array}{l}0.84 \\
0.69 \dagger\end{array}$ & $\overline{0} \cdot 75+$ & $\overline{0} \cdot 70 \dagger$ \\
\hline $\begin{array}{l}\text { Providing programme information by personal } \\
\text { postcard }\end{array}$ & - & $0 \cdot 79+$ & - & - \\
\hline Population size $(n=1832)$ & $0.57 \dagger$ & $0.63 \dagger$ & $0.65 \dagger$ & $0.54 \dagger$ \\
\hline
\end{tabular}

* The ORs summed in this table are the result of the multiple logistic regression analysis: In the table - means that this factor was not selected from first stage analysis in its related age group for multiple analysis.

$+\mathrm{p}<0.05$.

GHE = general health examination programme

$\mathrm{BCS}=$ breast cancer screening programme. networks. The participant in the screening programme in the community differs from the patient who seeks medical care in hospital. The former is one of the "normal population", and his or her motive for taking advantage of the service is not so strong as that of the patient. According to behaviour theories, ${ }^{9}{ }^{10}$ knowledge about and belief in the related health issue is essential for participation. Thus, effective methods of providing information about the programme and its importance are the key to motivation.

According to the results, the more common and easier, but less personal, methods of providing information, such as newsletters and house to house circulars do not seem to be effective in increasing the participation rate. Personal methods, such as home visits by public health nurses or by members of local community organisations, seem to be more effective. Members of local community organisations and nurses are important and influential in both local social networks in residents' daily lives, when they make a decision to take various examinations. Information about the screening programme can be provided more effectively by personal explanation. ${ }^{11}$ This sort of provision seems much more important for the elderly since community life is a greater part of their social activities. This could explain either the stronger association between the factor "getting the local cooperation" and the participation rate in the 60-69 years group, or for the weaker association in the 40-49 and the 50-59 years groups, as people in the latter two groups are usually at work all day. The stronger association of this factor in the small population group could also be explained by the lower migration and the closer relationships between residents in smaller communities.

Another feature is the accessibility of the screening programme. Current theories about utilisation of health care services have pointed out that the scheduling of, distance to, and associated procedures of the service contribute to high or low utilisation. For both large and small population groups and in each age group of this study, the factor "providing screening outside office hours" also showed itself to be positively associated with increased participation. In the 40-49 and the 50-59 years age groups, this factor showed a stronger association, which suggests that scheduling is more important to people who work. The positive association of the factor "conducting screening at the same time as the general health examination" in the 40-49 group may also be because most of this group work.

The third feature relates to the availability of resources for the screening programme. Resources comprise manpower, finance, facilities, technology, and information control. The factors "getting local cooperation" and "providing programme information through local organisation activities" both point to the positive effect of local voluntary cooperation. This cooperation not only means community participation in health decisions, but also provides a huge source of potential manpower to health 
care programmes. Another resource is the recording of data. The strongest positive association with the participation rate in all groups was that of "keeping records of those who had not participated in the screening for $\mathbb{R} 3$ years". In the small municipalities, "setting up a filing system of the records for individuals" also showed as a basic method. Record keeping is usually regarded as a step of the "postscreening management", but it is also the first step of the next cycle of service for each individual, and especially for those who have not participated in the screening for a few years. In large cities, the population size produces a great amount of data after the screening, so "using a computer in the filing system" makes information management much easier.

The style of operating methods reflects a set of characteristics of health care service programmes themselves. In other words, this study is concerned with the organisational aspect of health care-seeking behaviour. The practical importance of some factors analysed in this report has also been found in several other studies. ${ }^{12-14}$

Some regional and national studies have suggested that other issues are associated with the participation rate. These include the sex of the target population and other demographic characteristics (for example, occupation), ${ }^{15}$ views about health care and concern about getting cancer, ${ }^{1617}$ the type of health insurance, ${ }^{18}$ medical service after the screening, ${ }^{19}$ quality of the screening technology, ${ }^{20}$ screening frequency, ${ }^{21}$ health status of the community, and so on..$^{22}$ All of these are helpful in understanding possible barriers and keys to the successful implementation of all cancer screening programmes, not only the gastric one. Many of the issues are difficult for health care workers and administrators of the local municipalities to control or change but the factors analysed in this study are all operating methods used in the community based practice at present, which can be controlled and changed.

Among the factors listed above, sex is a striking one since the target population of the programme is people of 40 and over. Most Japanese women leave work after they get married and because of this community life provides a much greater part of their social activity. Therefore, the operating methods may be influenced by sex, and should therefore be managed with this borne in mind. We regret that we were unable to analyse this basic demographic factor in this study - unfortunately gender is not an item on the standardised form used in the reporting system.

Five kinds of cancer screening programmes (for stomach, lung, uterus, breast, and colon) have currently been enforced by the Ministry of Public Health and Welfare under the provisions of the Health and Medical Service for Aged Act of 1983. The findings from this study of a gastric cancer screening programme, such as personal methods for notification, mobilisation of the local volunteers, and filing system for individuals, could also be used for improving participation in the other screening programmes. Some results, however, such as providing an outside office hours service, may vary with the features of the different screenings. For example, screening for colon cancer is also a kind of screening of the digestive system and screening in the early morning may help improve the participation. Screening at noon rather than early morning may be better for screening for cervical and breast cancer for women aged 30 years and over, as the early morning is usually the busiest time for a housewife in Japan.

In conclusion, this study suggests that participation in the gastric screening programme could be increased and its efficiency could be raised, if we try to do the following:

(1) Provide higher quality information about the screening programme by more personal methods in order to motivate those targetted;

(2) Mobilise the manpower of local voluntary organisations and give full play to their dominant roles in community affairs related to all process of the screening programme;

(3) Provide an outside office hours service (for example early morning) and combine screenings (for example with the general health examination) especially for those who work;

(4) Set up records of those who have not participated for a few years, and a basic filing system for individual data with or without the use of computers.

The results in this study may provide a reference for improving participation in other cancer screening programmes.

The authors are particularly grateful to Dr Atsuhiko Tsukuda, Dr Masaki Nagai, Dr Yosikazu Nakamura, Dr Toshiyuk Ojima and the staff of the Department of Public Health in Jichi Medical School for their support and interest; they thank the 3268 Japanese municipalities for their cooperation.

1 Health and Welfare Statistics Association. The process of cancer preventive strategies. Trend of national health. Special volume of Kosei No Shihyo (Health Index) 1992;39:111-5. (In Japanese)

2 Statistics and Information Department. Minister's Secretariat, Ministry of Health and Welfare. Vital Statistics of fapan. Tokyo: Ministry of Health and Welfare, 1990:254-5.

3 Health and Welfare Statistics Association. Special volume for cancer issue. Kosei No Shihyo (Health Index) 1980;27:8-9. (In Japanese)

4 Hirayama T. Outline of stomach cancer screening in Japan. In: Screening in cancer. A report of UICC International Wn: Screening in cancer. A report of UICC Inter

5 Ministry of Health and Welfare. The health and medical services for the aged act and its related regulations. Tokyo: Ministry of Health and Welfare, 1990:479-83. (In JapanMinist

6 Ministry of Health and Welfare. The annual data list of health map of the municipalities in fapan. Tokyo: Ministry of Health and Welfare, 1990.

7 Statistics Bureau, Management and Coordination Agency. Population Census of fapan 1990. Tokyo: Janpan Statistics Association, 1991

8 Wang B, Sakata K, Nakamura Y, Nagai K. A study on an efficient system of gastric cancer screening in the community in Japan: the relationship between the operating style of the screening program and the population size of municipalities. F Epidemiol 1993;3(1):11-18.

9 Mechanic D. Strategies for health promotion. In: Proceedings of the Second International Conference of Health Behavioral Science in Tokyo, Sept 27-29, 1991:4-11.

10 Leventhal $\mathrm{H}$. The integration of emotion and recognition: a view from the perceptual motor theory of emotion. In: view from the perceptual motor theory of emotion. In: Clarke M, Fiske F, eds. The seventeenth annual Carnegie symposium on recognit

11 Mckinlay BJ. Social networks, lay consultation and helpseeking behavior. Social Forces 1973;51:275-91.

12 Yanagawa $H$, Nagai $M$, Sakata $K$, Wang B, Fujita $Y$ Current status and problems of mass screening for cancer. Current status and problems of mass scre
Asian Medical fournal 1992;35:656-63.

13 Tsuji I, Fukao A, Hisamichi S, et al. The influence of informing media on the participation rate of gastric cancer 
screening program. Kosei No Shihyo (Health Index) 1991;38:22-7. (In Japanese)

14 Fujisaki T, Sekita Y. Evaluation of the effect of gastric cancer examination: an approach model of an efficient program of gastric cancer screening. Fournal of Gastroenterological Mass Survey 1984;3:85-93. (In Japanese)

15 Sugawara N, Fukao A, Takahashi H. A study on the community-based health examination related to the gastric cancer screening. Kosei No Shihyo (Health Index) 1990;37:23-8. (In Japanese)

16 Tanaka T, Tsushima S, Morio S, et al. An analysis of the participation of residents in the community to cancer screening. Kosei No Shihyo (Health Index) 1990;37:21-8. (In Japanese)

17 Sonoda K. The participation behavior of Tokyo residents to a mass health examination program. Kosei No Shihyo a mass health examination program. Koset No Shihyo
(Health Index) 1990;35:3-10. (In Japanese)

18 Watanabe $\mathrm{M}$, Yosida Y, Kono $\mathrm{K}$, et al. The perceived health status of the residents in suburbs nearby a big city and their participation in mass examination program. Kosei No Shihyo (Health Index) 1990;37:12-18. (In Japanese)

19 Hiraga M, Kota S. A survey of participants who need continuous care in the mass health examination program Kosei No Shihyo (Health Index) 1985;32:18-23. (In Japanese)

20 Nishizawa $M$, Nomoto $\mathrm{K}$, Hosoi D, et al. Problems in gastric cancer mass screening and their improvement (II): Various methods of mass screening and evaluation of their efficiency. Fournal of Gastricenterological Mass Survey 1993;53:42-6. (In Japanese)

21 Yanagawa $H$, Yokoyama $H$, Nagai $M$. An evaluation of the effect of a cervical cancer mass screening program. Kosei
No Shihyo (Health Index) 1981;28:22-8. (In Japanese)

22 Rosenstock I. Why people use health service. Millbank Memorial Fund Quarterly 1966;44:94-127.
Mestock I. Why people use health ser 